\title{
Maternal postpartum morbidity in Marrakech: what women feel what doctors diagnose?
}

\author{
Bouchra Assarag ${ }^{1,2,3^{*}}$, Dominique Dubourg ${ }^{2}$, Abderrahmane Maaroufi $^{1}$, Bruno Dujardin $^{3}$ and Vincent De Brouwere ${ }^{2}$
}

\begin{abstract}
Background: Information about postpartum maternal morbidity in developing countries is limited and often based on information obtained from hospitals. As a result, the reports do not usually reflect the true magnitude of obstetric complications and poor management at delivery. In Morocco, little is known about obstetric maternal morbidity. Our aim was to measure and identify the causes of postpartum morbidity 6 weeks after delivery and to compare women's perception of their health during this period to their medical diagnoses.

Methods: We did a cross-sectional study of all women, independent of place of delivery, in Al Massira district, Marrakech, from December 2010 to March 2012. All women were clinically examined 6 to 8 weeks postpartum for delivery-related morbidities. We coupled a clinical examination with a questionnaire and laboratory tests (hemoglobin).

Results: During postpartum consultation, $44 \%$ of women expressed at least one complaint. Complaints related to mental health were most often reported (10\%), followed by genital infections (8\%). Only $9 \%$ of women sought treatment for their symptoms before the postpartum visit. Women who were aged $\geq 30$ years, employed, belonged to highest socioeconomic class, and had obstetric complications during birth or delivered in a private facility or at home were more likely to report a complaint. Overall, $60 \%$ of women received a medical diagnosis related to their complaint, most of which were related to gynecological problems (22\%), followed by laboratory-confirmed anemia (19\%). Problems related to mental health represented only $5 \%$ of the diagnoses. The comparative analysis between perceived and diagnosed morbidity highlighted discrepancies between complaints that women expressed during their postpartum consultation and those they received from a physician.
\end{abstract}

Conclusions: A better understanding of postpartum complaints is one of the de facto essential elements to ensuring quality of care for women. Sensitizing and training clinicians in mental health services is important to respond to women's needs and improve the quality of maternal care.

Keywords: Maternal health, Postpartum maternal morbidity, Women's perceptions, Morocco

\section{Background}

In light of trends in the worldwide maternal mortality, it is commonly acknowledged that the fifth Millennium Development Goal is not likely to be achieved by 2015 [1]. Nevertheless, maternal mortality represents only the tip of the iceberg of the much larger issue of maternal morbidity [2]. Estimates suggest that among the 136 million women who give birth every year, about 1.4 million experience life-threatening medical emergencies, 9.5

\footnotetext{
* Correspondence: Bassarag@gmail.com

${ }^{1}$ National Institute of Health Administration, BP: 6329 Rabat, Morocco

${ }^{2}$ Institute of Tropical Medicine, Nationalestraat 155, B-2000 Antwerp, Belgium

Full list of author information is available at the end of the article
}

million experience other complications, and 20 million have long-term disabilities [3-6]. These morbidities have different etiologies; some are related to the quality of care during pregnancy and delivery, and others are related to a broader set of social and personal factors.

Depending on the definition, we have different estimates for maternal morbidity. If we take severe acute maternal morbidity as defined by the World Health Organization (WHO) in 2010 as "a woman who nearly died but survived a complication during pregnancy, childbirth, or within 42 days of pregnancy termination through care in health facilities," [7], prevalence rates of life-threatening medical emergencies in many countries varies from $0.6 \%$

\section{Biomed Central}


to $14.98 \%$ using disease-specific criteria, $0.04 \%$ to $4.54 \%$ using management-based criteria, and $0.14 \%$ to $0.92 \%$ using organ-based dysfunction based on Mantel criteria [8]. Rates are higher in the low- and middle-income countries of Asia and Africa (eg, Benin, Cote d'Ivoire, Morocco, Indonesia) $[9,10]$. These variations might be due to real epidemiological differences in different populations or to differences in the definitions and approaches of maternal morbidity.

The lack of harmonization of these criteria makes it difficult to establish priorities in terms of assistance and treatment in maternal and infant health, especially in countries with limited resources. Morbidity data are vital for policymakers and health care planners who need to know how many women require essential obstetric care $[11,12]$. Studies on postpartum morbidity have been scarce in Morocco. Only one study, conducted in 2001, measured the proportion of hospital admissions for acute maternal morbidity during pregnancy, childbirth, and postpartum [13]. Usually, many reproductive disorders go unnoticed, because they cause no symptoms or only nonspecific symptoms. Because of a lack of or incomplete information due to poor documentation, we measured self-described postpartum morbidity in a group of postpartum women living in Marrakech, along with their sociodemographic factors, to compare women's postpartum complaints with medical diagnoses.

\section{Methods}

\section{Context}

In Morocco, antenatal and postnatal care is provided in all 2,689 public health centers and in the private sector. Antenatal coverage is about $77 \%$ (92\% in urban areas and 63\% in rural areas). About half of pregnant women have their prenatal consultation in the private sector. Most deliveries take place in public hospitals $(51.5 \%)$ or in the 606 firstlevel public delivery houses managed by midwives and general practitioners (12\%); $26.8 \%$ of women deliver at home. Only $9.2 \%$ of women deliver in private hospitals [14].

\section{Study site}

This descriptive study was carried out in Al Massira health district. This district, $10 \mathrm{~km}$ outside of Marrakech, Morocco, has a population of 106,000. Maternal health services in the district are offered by a public 'delivery house' (peripheral primary level), a private clinic, 16 private general physicians, three private laboratories, and 11 private pharmacies. In case of complications, women are referred to the secondary-level regional hospital or the tertiary-level university hospital in Marrakech.

\section{Study population}

Our study included all women aged 18 to 49 in the $\mathrm{Al}$ Massira district who had delivered between December 2010 and March 2012 in the delivery house, hospital maternity wards, or private clinics. Women who had delivered at home were also eligible for inclusion, and we identified them through the civil registration system and during their newborns' BCG vaccination.

\section{Postpartum consultation procedures}

There were 1,550 deliveries recorded in $\mathrm{Al}$ Massira district; 20 of these women, all single, refused to answer questions or be recruited. Thus, 1,530 women were initially included in the study and were interviewed by a midwife about their socioeconomic and demographic characteristics using a pretested questionnaire (Figure 1). The midwife invited them to attend a postpartum consultation at the nearest delivery house 6 weeks after delivery after a prepaid laboratory blood examination. The consultation consisted of a 30-minute interview followed by semistructured and openended questions about any postpartum complaint they had experienced and a physical examination by a doctor.

Psychological morbidity was identified through a few symptoms representing mental distress (eg, feeling negative about yourself, crying easily, decreased interest or pleasure in daily activities) in the last 2 weeks that represented a change from normal (Additional file 1 adapted from the 2001 WHO report [15]). Seven doctors and nine midwives were trained as investigators by a professor of obstetrics and gynecology from the Marrakech University Hospital. The 2-day interactive training consisted of teaching the standard operating procedure for interviewing and examining women and discussing the case definitions (Additional file 1 adapted from [16-19]).

If a woman missed her appointment, the principal investigator tried to reach her by telephone. If she then requested that the consultation be done at her home, we had a female physician fill out the questionnaire and conduct the medical examination at home. If the woman refused to participate, she was excluded from the study. All women who received a diagnosis of any morbidity or disability were treated by the study doctor or referred to a specialized hospital, where they received care free of charge, depending on their diagnosis. The conditions identified between the sixth and the eighth weeks postpartum were defined on the basis of standard clinical protocols and specific tests, as indicated in Additional file 1 . These definitions were operationalized and in line with the WHO guidelines [20].

\section{Data analysis}

Data were entered into an Epi Info ${ }^{\mathrm{Tm}}$ Version 3.5.3 database. IBM SPSS Statistics for Windows, Version 20, was used for analysis. Descriptive analysis was used for sociodemographic and reproductive characteristics. To determine the socioeconomic characteristics of the women and their households, quintiles of wealth were generated using principal-component analysis based on the eligibility 


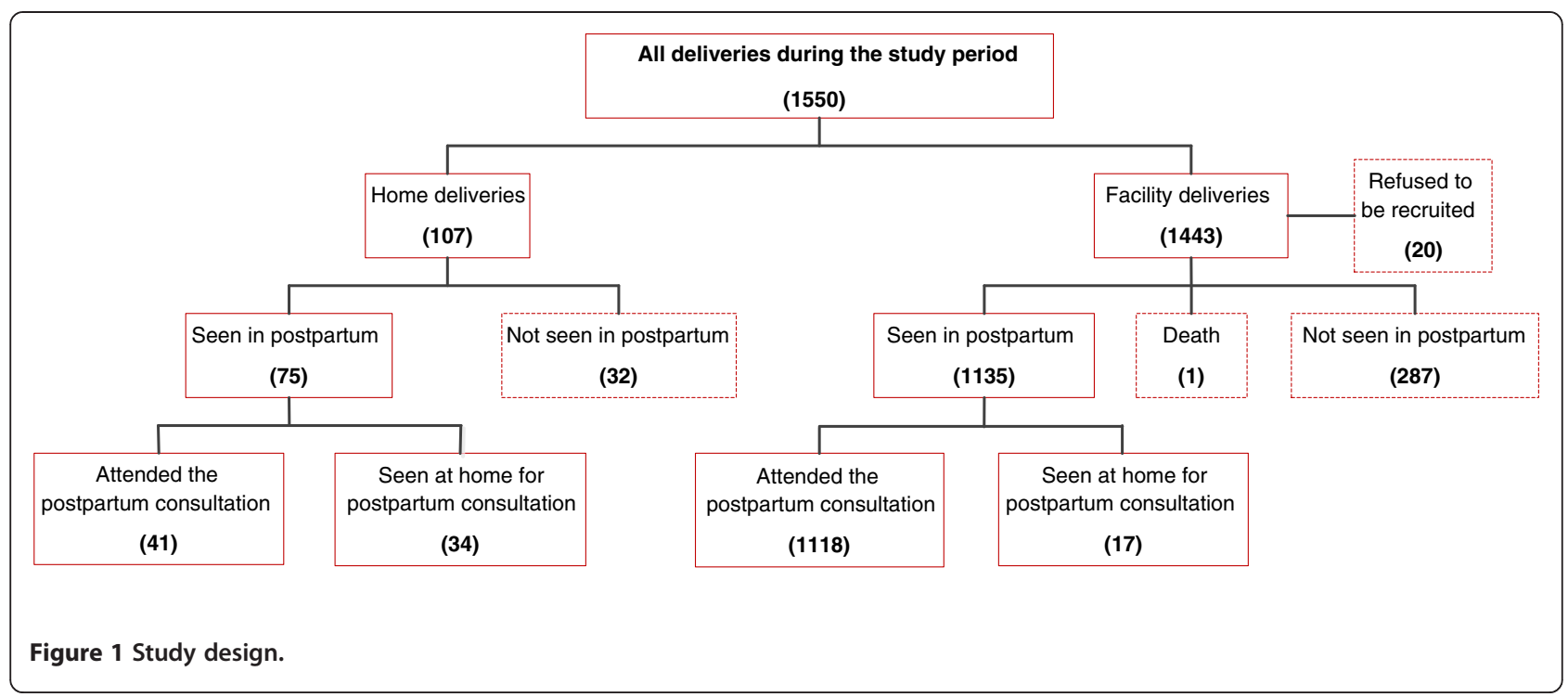

criteria used by Moroccan authorities to classify insurance beneficiaries (eg, possession of household commodities, homeownership). Pearson's chi-square test was used for the crude association between the women's postpartum morbidities and selected reproductive and sociodemographic characteristics. Women's complaints were standardized and categorized to facilitate their comparison with diagnoses established by the medical doctor.

The standardization of complaints was performed by grouping complaints with similar symptoms into one category (ie, "constipation," "did not go to the toilet," "did not go to the toilet for a week" were grouped into the category "constipation"). If a woman had several complaints, we prioritized the first. For the analysis, we calculated the cumulative number of complaints for all women and then categorized them, excluding complaints without a direct link to the delivery and problems related to previous diseases (eg, asthma, goiter).

We classified the clinical diagnoses established by the medical doctors according to their definitions and clinical signs. We grouped similar diagnoses into single categories and developed a standard classification (eg, vaginitis, vulvar-vaginitis, cervicitis, vulvitis, and candidiasis were grouped under the category "genital infections"). If we had several different diagnoses for the same woman, we calculated the proportions of each of the cumulative diagnoses using the number of women consulting after delivery as the denominator.

\section{Ethical consideration}

The study protocol was approved by the Ethical Committee of the Institute of Tropical Medicine Antwerp, the University Hospital of Antwerp in Belgium, and the Ethical Committee for Biomedical Research of Mohammed V
University of Morocco in November 2010. We informed all eligible women about the purpose of the study and their rights and collected their written and oral consent before they were enrolled.

\section{Results}

Of the 1,530 women recruited, 1,210 women attended a postpartum consultation. One death was reported following a hemorrhagic episode during delivery complicated by the Hemolysis Elevated Liver enzymes Low Platelet count (HELLP) syndrome. Regarding the sociodemographic characteristics of the 1,210 participants, $6 \%$ were younger than 20 years, and $44 \%$ were older than 30 . Mean age was 29 years. Only 13 were single, and $23 \%$ had not received any formal education (Table 1).

Three hundred-twenty (21\%) women did not attend the postpartum consultation. In general, these women had a lower level of education $(\mathrm{p}=0.0001)$, a lower socioeconomic score $(\mathrm{p}<0.001)$, and higher parity $(\mathrm{p}=0.0001)$. Among the 1,210 women who attended a postpartum consultation, 893 (74\%) did not have medical insurance, and 91\% were unemployed. Most women (87\%) had fewer than three children, and $32 \%$ were primigravidae. Nineteen percent of women had had at least one abortion (data not shown). The vast majority (94\%) of women had delivered in a health facility; more than two-thirds (71\%) had delivered in a delivery house, $10 \%$ in a private hospital, $7 \%$ at the university hospital, and 6\% at the regional hospital. In $79 \%$ of deliveries, women decided on their own where to deliver their baby. More than one-third (35\%) had at least one complication during delivery. Life-threatening emergencies represented $6 \%$ of the hospital's deliveries in our study. 
Table 1 Reproductive and sociodemographic characteristics of women $(N=1,530)$

\begin{tabular}{|c|c|c|c|}
\hline \multirow[t]{3}{*}{ Characteristic } & \multicolumn{2}{|c|}{ Number (\%) } & \multirow[t]{3}{*}{$P$ value } \\
\hline & $\begin{array}{l}\text { Women with } \\
\text { postpartum } \\
\text { consultation }\end{array}$ & $\begin{array}{l}\text { Women without } \\
\text { postpartum } \\
\text { consultation }\end{array}$ & \\
\hline & $n=1,210$ & $n=320$ & \\
\hline \multicolumn{4}{|l|}{ Age } \\
\hline$<20$ & $68(6)$ & $24(7)$ & \multirow[t]{6}{*}{0.6} \\
\hline $20-25$ & $271(22)$ & $66(21)$ & \\
\hline $25-30$ & $338(28)$ & $96(30)$ & \\
\hline $30-35$ & $336(28)$ & $83(26)$ & \\
\hline$>35$ & $197(16)$ & $50(16)$ & \\
\hline Unknown & 0 & $1(0)$ & \\
\hline \multicolumn{4}{|l|}{ Education level } \\
\hline None & $273(22)$ & $118(37)$ & \multirow[t]{5}{*}{0.0001} \\
\hline Primary & $406(34)$ & $106(3)$ & \\
\hline High school & $356(29)$ & $70(22)$ & \\
\hline Higher education & $175(15)$ & $25(8)$ & \\
\hline Unknown & $0(0)$ & $1(0)$ & \\
\hline \multicolumn{4}{|l|}{ Medical insurance } \\
\hline No & $892(74)$ & $248(78)$ & \multirow[t]{3}{*}{0.1} \\
\hline Yes & $318(26)$ & $71(22)$ & \\
\hline Not known & $0(0)$ & $1(0)$ & \\
\hline \multicolumn{4}{|l|}{ Occupation } \\
\hline No & $1102(91)$ & $292(91)$ & \multirow[t]{3}{*}{0.9} \\
\hline Yes & $108(9)$ & $27(9)$ & \\
\hline Unknown & 0 & $1(0)$ & \\
\hline \multicolumn{4}{|l|}{ Homeowner } \\
\hline No & $584(48)$ & $159(50)$ & \multirow[t]{3}{*}{0.7} \\
\hline Yes & $612(51)$ & $160(50)$ & \\
\hline Unknown & $14(1)$ & $1(0)$ & \\
\hline \multicolumn{4}{|c|}{ Socioeconomic score (quintile) } \\
\hline Poorest & $189(16)$ & $110(34)$ & \multirow[t]{6}{*}{$<0.001$} \\
\hline Less poor & $198(16)$ & $0(0)$ & \\
\hline Average & $266(22)$ & $133(42)$ & \\
\hline Less rich & $239(20)$ & $60(19)$ & \\
\hline Richest & $283(23)$ & $16(5)$ & \\
\hline Unknown & $35(3)$ & $1(0)$ & \\
\hline \multicolumn{4}{|l|}{ Obstetric history } \\
\hline \multicolumn{4}{|l|}{ Parity } \\
\hline 1 & $382(32)$ & $137(43)$ & \multirow[t]{4}{*}{0.0001} \\
\hline $2-3$ & $672(55)$ & $154(48)$ & \\
\hline 4 or more & $156(13)$ & $28(9)$ & \\
\hline Unknown & $0(0)$ & $1(0)$ & \\
\hline
\end{tabular}

Table 1 Reproductive and sociodemographic characteristics of women ( $N=1,530)$ (Continued)

\begin{tabular}{llll}
\hline Delivery structure & & & \\
At home & $75(6)$ & $32(10)$ & 0.0001 \\
University hospital & $78(7)$ & $27(8)$ & \\
Private sector & $119(10)$ & $14(4)$ & \\
Regional maternity & $75(6)$ & $35(11)$ & \\
Delivery house & $863(71)$ & $211(66)$ & 0.01 \\
Unknown & $0(0)$ & $1(0)$ & \\
Type of delivery & & $177(55)$ \\
Vaginal & $576(48)$ & $102(32)$ & \\
Vaginal + episiotomy & $426(35)$ & $28(9)$ & \\
Cesarean section & $122(10)$ & $12(4)$ \\
Vacuum or forceps & $86(7)$ & $0(0)$ & \\
Unknown & $0(0)$ &
\end{tabular}

\section{Postpartum problems}

During the postpartum consultation, 538 (44\%) of the 1,210 women expressed at least one complaint, for 608 cumulative complaints (Table 2). However, $91 \%$ of women did not consult a doctor for these complaints. Of women who did not have complications during delivery, $42 \%$ mentioned a complaint that occurred during the 6- to 8-week postpartum phase. During the postpartum consultation, mental distress (anxiety, unexplained crying, nervousness) was the most commonly cited complaint (10\%), followed by genital infections (vaginal discharge, vaginal leaking) $(8 \%)$, and breast problems (5\%). Other gynecological and obstetric problems (sexual problems, uterine prolapse, and infected episiotomy) were also reported (10\%). Finally, burning during urination and urinary leakage were reported in $2 \%$ and $1 \%$ of women, respectively.

\section{Diagnoses in postpartum period}

A total of $729(60 \%)$ women received a diagnosis of a complication from a medical doctor. Among them, 9\% received more than one diagnosis. The most common medical diagnosis was related to gynecological problems (22\%) (genital infection, uterine prolapse, cystocele, bad repair of an episiotomy), followed by laboratory-confirmed anemia (19\%). Mental distress were one of the least common diagnoses (5\%). Doctors based their diagnosis of anemia on the blood cell count and classified it as mild anemia $(9<\mathrm{Hb} \leq 11 \mathrm{~g} / \mathrm{dL})$, moderate $(\mathrm{Hb} \geq 7-9 \mathrm{~g} / \mathrm{dL})$, or severe $(\mathrm{Hb}<7 \mathrm{~g} / \mathrm{dL})$. Sixteen percent of women received a diagnosis of mild anemia, $3 \%$ had moderate anemia, and one woman had severe anemia (Table 3).

\section{Self-complaints versus medical diagnoses}

Complications diagnosed by doctors did not always correspond to women's self-reports. When we compared their 
Table 2 Complaints by women who attended the postpartum consultation $(n=1,210)$

\begin{tabular}{lll}
\hline $\begin{array}{l}\text { Cumulative complaint categories during } \\
\text { postpartum (6-8 weeks after delivery) }\end{array}$ & Frequency & \%* \\
\hline Psychological & 124 & 10 \\
Vaginal discharge & 98 & 8 \\
Hemorrhoids & 70 & 6 \\
Breast problems & 63 & 5 \\
Weariness & 35 & 3 \\
Problems of episiotomy & 29 & 2 \\
Prolapse & 29 & 2 \\
Sexual problems & 27 & 2 \\
Anal problems & 25 & 2 \\
Urinary burning & 22 & 2 \\
Bleeding & 20 & 2 \\
Vulvar itching & 19 & 2 \\
Pelvic problems & 17 & 1 \\
Hypertension & 15 & 1 \\
Urinary leakage & 11 & 1 \\
Other & 21 & 2 \\
Total & 608 & 50
\end{tabular}

*The proportion was calculated using data from the 1,210 women who had a postpartum consultation. However, a woman could have reported more than one complaint

'Other: infection of cesarean section wound, cycle disorder, heart palpitations.

self-reported complaints to the medical diagnoses made during the postpartum consultation, the most divergent proportions were mental distress and anemia (Table 4).

We used bivariate analysis to assess the strength of the association between the selected demographic and reproductive characteristics and the women's self-reports of postpartum complaints.

Table 3 Cumulative number of medical diagnoses ( $n=1,210$ )

\begin{tabular}{lll}
\hline $\begin{array}{l}\text { Cumulative category of diagnoses during } \\
\text { postpartum (6-8 weeks after delivery) }\end{array}$ & Frequency & \%* \\
\hline Gynecological & 266 & 22 \\
Anemia & 224 & 19 \\
Hemorrhoids & 110 & 9 \\
Breast & 68 & 6 \\
Psychological & 64 & 5 \\
Perianal & 55 & 4 \\
Hypertension & 23 & 2 \\
Urinary incontinence & 22 & 2 \\
Urinary infection & 20 & 1 \\
Total & 852 & 71 \\
\hline
\end{tabular}

*The proportion was calculated using data from the 1,210 women who had a postpartum consultation. However, the same woman could have had more than one diagnosis.
Table 4 Self-reported complaints versus observed diagnoses during postpartum consultation

\begin{tabular}{lllll}
\hline Morbidity $(\mathbf{n}=\mathbf{1 , 2 1 0})$ & \multicolumn{2}{c}{ Complaints } & \multirow{2}{P}{ value } \\
\cline { 3 - 4 } & & Yes & No & \\
\hline Medical diagnosese & Yes & $458(85)$ & $272(40)$ & 0.0001 \\
n (\%) & No & $80(15)$ & $400(60)$ & \\
Total & & $538(100)$ & $672(100)$ & \\
\hline
\end{tabular}

We found the highest prevalence of complaints reported by women $\geq 30$ years, women who were employed, women who had delivered at home or in the private sector, and those who had complications during delivery (Table 5).

\section{Discussion}

Information on postpartum morbidity in developing countries is limited and, when available, usually describes the type of medical condition diagnosed at the hospital level. This is the first study conducted in Morocco comparing postpartum morbidity diagnosed by a physician vs. selfreported morbidity among women. In this study, $44 \%$ of women reported postpartum problems. This prevalence is high, and the morbidities were a mixture of benign and severe. The most common type of problem was psychological $(10 \%)$ and reveals that mental distress that should be addressed because it is an indicator of postpartum depression [21].

Table 5 Factors influencing women's reported complaints in the postpartum period

\begin{tabular}{lll}
\hline Determinants & $\begin{array}{l}\text { Women with } \\
\text { complaints n (\%) }\end{array}$ & $\begin{array}{l}\text { P value } \\
\text { (chi square) }\end{array}$ \\
\hline Age & $277(41)$ & 0.003 \\
$<30$ years & $261(49)$ & \\
$\geq 30$ years & & \\
Employed & $481(44)$ & 0.04 \\
No & $57(53)$ & \\
Yes & & \\
Place of health care delivery & $347(40)$ & 0.0001 \\
First-level delivery house & $43(57)$ & \\
Second-level regional maternity & & \\
Place of delivery & $494(44)$ & \\
Facility health & $44(58)$ & \\
Home & & \\
Sector of delivery & & \\
Public sector & $431(42)$ & \\
Private sector & $63(53)$ & 0.004 \\
Complications during delivery & & \\
No & $333(42)$ & \\
Yes & $205(49)$ & \\
\hline & & \\
\hline
\end{tabular}


The prevalence is lower than the prevalence of postnatal depression (18.6\%), anxiety (13.1\%), and stress $(8.7 \%)$ found in a representative sample of Qatari women who attended a primary health care postpartum consultation within 6 months after delivery [22]. Other studies in Australia [23] and Zimbabwe [24] showed similarly high levels of postnatal depression (17.4\% and $16 \%$, respectively). The WHO and the United Nations Population Fund reported $10 \%-15 \%$ postnatal depression in industrialized countries [25]. However, in our study, we did not specifically look for this type of health outcome. Certainly, our findings suggest the need to further explore postpartum mental disorders using appropriate tools. We hope that, given that mental distress ranked first among all self-reported postpartum health problems, postpartum depression in Morocco will receive more attention and bring postnatal depression 'out of the shadows' [26]. The second most common complaint was symptoms of genital infections (8\%). It should be noted that $91 \%$ of women did not seek care.

The reasons given for not seeking care were distance from home to the maternity hospital, no pain, a bad experience during childbirth (for those who delivered at the regional maternity hospital), and fear of having a serious illness. These factors should be further studied so that interventions can be defined and implemented to increase the number of women who seek medical care for postpartum health problems. Subnotification of pathologies compared with observed measurements was demonstrated to be influenced first by age, education, and socioeconomic level and, second, by asymptomatic or vague signs of genital infection [27].

Our study also shows that a high proportion of women (60\%) were given a diagnosis of a postnatal problem 6 to 8 weeks after delivery. Similar levels of prevalence, or higher (72\%), were reported in other studies $[16,28]$. As with the prevalence of self-reported complaints, these medical diagnoses are a mixture of severe and benign. Only 12 women (1\%) who attended the 42-day postpartum consultation had a severe condition such as an infected perineal tear, infected caesarean section or episiotomy wound, third-degree uterine prolapse, cervical cancer, or severe anemia. These women, who apparently were not aware of the severity of their problem, were immediately referred to the university hospital.

Of interest, only $85 \%$ of diagnoses were aligned with women's self-reported complaints. Two health problems, in particular, account for this difference: psychological complaints and diagnoses of anemia. The physician recognized psychological complaints in only $5 \%$ of women, only half of the women who voiced such a complaint. Informal discussions with physicians indicate that they often did not take this type of complaint seriously, implying that anxiety, stress, tiredness, or crying were 'normal' in postpartum women and not important enough to be diagnosed or treated. Moreover, in Moroccan physicians' training, significantly more attention is devoted to physical health than to mental health. Anemia was diagnosed in $19 \%$ of women, but only a small proportion of them complained of symptoms that could be attributed to anemia, and none were from women with hemoglobin $>10 \mathrm{~g} \mathrm{Hb} / \mathrm{dL}$. Physicians were able to diagnose anemia in this instance because the women were invited to take the laboratory test for free. Under normal circumstances, women would have to pay to get the test, and most would be unable to pay. The question remains as to whether a more specific test (eg, ferritin to measure iron stock) is required before treating anemia with iron.

Estimates of self-assessed morbidity prevalence are generally more specific than sensitive [29]. Underestimation or overestimation by women tends to be influenced by age, level of education, and specificity of clinical symptoms [27]. In industrialized countries, greater value is given to women's self-reports of complaints, and responding to these complaints is considered more important than measuring the prevalence of true postpartum morbidity $[2,30,31]$.

Today in Morocco, the proportion of women who attend a postnatal consultation at 6 weeks is $22 \%$ [14]. We believe that our study has brought clear advocacy arguments to increase this percentage. In our study, we were able to reach $80 \%$ of potential subjects by recruiting women at delivery and inviting them to return 6 weeks later for a health consultation by providing a voucher to get a free blood test and calling the small proportion of women who did not show up for their appointment.

\section{Limitations}

This study had several limitations. First, although reminders were sent and women were called by phone, $20 \%$ did not attend the postnatal consultation, either because they did not want to or they had moved. This relatively high loss to follow up after delivery may have biased our results. We recorded the sociodemographic characteristics of these women and compared them with those who attended the consultation. Women with a lower education level, lower socioeconomic status, primiparae, delivered at home or at the regional hospital, and who did not have a complication were less likely to attend the postnatal consultation. Second, psychological complaints were recorded only when women brought them up themselves, but we did not specifically ask questions about mental distress to screen for postpartum depression as part of the standard interview. Therefore, it is likely that our findings are an underestimate of the 
true burden of this problem. Third, of a total of 43 single mothers, only 23 were recruited, and 20 of them did not agree to participate. This was likely a missed opportunity to investigate a particularly vulnerable group of women.

\section{Policy implications}

A strategy to reduce morbidity, along within increased political backing and resources, are clearly needed to expand the scope of current programs to address the full range of maternal morbidities. Preventive strategies are focused on the prenatal and on the delivery period; however, our study highlighted the importance of addressing health problems experienced during the postpartum period. Integrated mechanisms to prevent or reduce the burden of the problems revealed by this study might consolidate and encourage the use of maternal health services. We must implement specific and innovative postpartum interventions and consider women's mental health. These interventions must be included as part of the continuum of care, from the prenatal period through the postpartum phase.

Our findings provided new information about postpartum problems experienced by women in the Marrakech area, where mental health disorders in postpartum women were often not addressed by their physician. We need to sensitize and train medical doctors to pay more attention to women's complaints (mental distress in particular) and appropriately manage them. In addition, the use of health services during pregnancy, at delivery, and during the postpartum period, is essential to avoid most obstetric complications, provided that they are quickly treated when they occur. Women's use of mental health services is equally important in preventing reproductive morbidity. Their use of these services will depend on the woman's perception of need, as well as on the availability, accessibility and, especially, the quality of these services.

\section{Conclusions}

This analysis of the magnitude of postpartum morbidity revealed a possible hidden burden among Moroccan women. The comparison of women's perceptions with their medical diagnoses highlighted the need to train physicians to listen to their patients and recognize the signs of psychological distress. Indeed, postpartum consultation should take into account women's complaints, which are often not acknowledged or expressed. This study showed the importance of late (6 weeks) postpartum consultations. We were able to reach $80 \%$ of women in this study because women were invited at hospital discharge after delivery to attend the consultation and were actively followed by phone to remind them of their appointments. Making postpartum maternal morbidity a priority on the national agenda will help the fight against obstetric complications, which is critical to the wellbeing of women and their infants.

\section{Additional file}

Additional file 1: Definitions and diagnostic tools selected by physicians who performed the postpartum consultations.

\section{Competing interests}

The authors declare that they have no competing interests.

\section{Authors' contributions}

$B A, A M$, and VDB designed the study. BA conducted the study under the supervision of VDB. BA, VDB, and DD analyzed the data. BA wrote the initial draft of the manuscript. $V D B, B D$, and DD reviewed and critically revised the manuscript. All authors read and approved the final manuscript.

\section{Acknowledgements}

We thank all the clinicians, midwives, and women who participated in this study for their time. Special thanks go to the Health Authority of Marrakech, Dr. Bouanani Driss, Mrs. Bellal Ilham, and Dana A. Schneider.

\section{Author details}

${ }^{1}$ National Institute of Health Administration, BP: 6329 Rabat, Morocco.

${ }^{2}$ Institute of Tropical Medicine, Nationalestraat 155, B-2000 Antwerp, Belgium.

${ }^{3}$ Université Libre de Bruxelles, route de Lennik 808, 1070 Brussels, Belgium.

Received: 22 May 2013 Accepted: 29 November 2013

Published: 5 December 2013

\section{References}

1. UNDP: The Millennium Development Goals: Noted'orientationsur l'OMD5. New York; 2011:1-20. http://www.undp.org/content/dam/undp/library/ Democratic\%20Governance/Note\%20d\%27orientation\%200DM\%205.pdf

2. Fortney JA, Smith JB: The base of the iceberg: prevalence and perceptions of maternal morbidity in four developing countries. In The maternal morbidity network. Research Triangle Park, NC: Maternal and Neonatal Health Center, Family Health International; 1997:116.

3. World Health Organization: Trends in maternal mortality: 1990-2008. Geneva: World Health Organization; 2010:45.

4. Ashford L: Hidden suffering: disabilities from pregnancy and childbirth in less developed countries. Measure communication policy brief. Population Reference Bureau: Washington, DC; 2002.

5. Filippi V, Ronsmans C, Campbell OMR, Graham WJ, Mills A, Borghi J, Koblinsky M, Osrin D: Maternal health in poor countries: the broader context and a call for action. Lancet 2006, 368(9546):1535-1541.

6. Say L, Pattinson R, Gulmezoglu A: WHO systematic review of maternal Morbidity and mortality: the prevalence of severe acute maternal morbidity (near miss). Reproductive Health 2004, 1:3.

7. Pattinson R, Say L, Souza JP, Van den Broek N, Rooney C: WHO maternal death and near-miss classifications. Bull World Health Organ 2009, 87(10):734.

8. Tuncalp O, Hindin M, Souza J, Chou D, Say L: The prevalence of maternal near miss: a systematic review. BJOG 2012, 119:653-661.

9. Filippi V: Maternity wards or emergency obstetric rooms? Incidence of near-miss events in African hospitals. Acta Obstet Gynecol Scand 2005, 84(1):11-16

10. Adisasmita A, Deviany PE, Nandiaty F, Stanton C, Ronsmans C: Obstetric near miss and deaths in public and private hospitals in Indonesia. BMC Pregnancy Childbirth 2008, 8:10.

11. Prual A, Bouvier-Colle MH, de Bernis $L$, Breart G: Severe maternal morbidity from direct obstetric causes in West Africa: incidence and case fatality rates. 2. Bulletin of World Health Organisation 2000, 78(5):593-602.

12. Ronsmans C: Severe acute maternal morbidity in low-income countries. Best Practice and Research Clinical Obstetrics and Gynaecology; 2009, 23:305-316.

13. Sahel A, De Brouwere V, Filippi V, Van Lerberghe V, Ronsmans C, Lardi M: Obstetric catastrophes barely just avoided: near misses in Moroccan hospitals. Cahiers d'études et de recherches francophones, Santé, Etudes originales 2001, 11(4):229-235.

14. Ministère de la Santé du Royaume du Maroc: Enquête Nationale sur la Population et la Santé Familiale [EPSF 2011] Rabat. In Direction de la Planification et des Ressources Financières, Ministère de la Santé du Maroc; 2012:122-142. 
15. World Health Organization: Rapport sur la santé dans le monde - la santé mentale: Nouvelle conception, nouveaux espoirs. World Health Organization; 2001:10-11.

16. Ferdous J, Ahmed A, Dasgupta SK, Jahan M, Huda FA, Ronsmans C, Koblinsky M, Chowdhury ME: Occurrence and determinants of postpartum maternal morbidities and disabilities among women in Matlab, Bangladesh. J Health Popul Nutr 2012, 30:143-158.

17. Dutta DC: Obstetric fistula, genital prolapse, urinary and faecal incontinence, UTI, pelvic inflammatory disease. Textbook of gynaecology. Calcutta: New Central Book Agency; 2005:120-519.

18. Bhatla N: Breast problem. In Jeffcoate's principles of gynaecology. Edited by Neerja B. New Delhi: Arnorld publisher; 2005:139, 725.

19. DeCherney AH, Nathan L: Current obstetric and gynaecological diagnosis and treatment. New York: NY McGraw-Hill; 2004:433-434.

20. World Health Organization: Pregnancy, childbirth, postpartum and newborn care: a guide for essential practice. Bulletin World Health Organization; 2003:43-96.

21. Rahman A, Surkan PJ, Cayetano CE, Rwagatare P, Dickson KE: Grand challenges: integrating maternal mental health into maternal and child health programmes. PLoS Med 2013, 10(5):e1001442.

22. Bener A, Gerber LM, Sheikh J: Prevalence of psychiatric disorders and associated risk factors in women during their postpartum period: a major public health problem and global comparison. International journal women's health 2012, 4:191-200.

23. Yelland J, Sutherland G, Brown SJ: Postpartum anxiety, depression and social health: findings from a population-based survey of Australian women. Biomed Central Public Health 2010, 10:771.

24. Nhiwatiwa S, Patel V, Acuda W: Predicting postnatal mental disorder with a screening questionnaire: a prospective cohort study from Zimbabwe. J Epidemiol Community Health 1998, 52(4):262-266.

25. WHO, UNFPA: Report of a UNFPAWHO international meeting: the interface between reproductive health and mental health. Hanoi, June 21-23, 2007. Geneva: Bulletin World Health Organization; 2009.

26. The Lancet: Bringing postnatal depression out of the shadows [Editorial]. Lancet 2012, 380:1621.

27. Rathore M, Swani SS, Gupta BL: Community based study of self reported morbidity of reproductive tract among women of reproductive age in rural area of Rajasthan. Indian J Community Med 2003, 28:117-121.

28. AkI OA, Ibrahim HK, Mamdouh HM: Perceived reproductive morbidity and treatment seeking behavior among ever married women in Siwa Oasis, Egypt. J Am Sci 2011, 7(7):6.

29. Sadana R: Measuring reproductive health: review of community-based approaches to assessing morbidity [In Process Citation]. Bulletin World Health Organisation 2000, 78(5):640-654.

30. Bhanderi MN, Kannan S: Untreated reproductive morbidities among ever married women of slums of Rajkot city, Gujarat: the role of class distance, providerattitudes, and perceived quality of care. J Urban Healt 2010, 87(2):254-260

31. Oakley A, Rajan L, Robertson P: A comparison of different sources of information about pregnancy and childbirth. J Biosoc Sci 1990, 22(4):477-487.

doi:10.1186/1471-2393-13-225

Cite this article as: Assarag et al:: Maternal postpartum morbidity in Marrakech: what women feel what doctors diagnose?. BMC Pregnancy and Childbirth 2013 13:225.

\section{Submit your next manuscript to BioMed Central and take full advantage of:}

- Convenient online submission

- Thorough peer review

- No space constraints or color figure charges

- Immediate publication on acceptance

- Inclusion in PubMed, CAS, Scopus and Google Scholar

- Research which is freely available for redistribution

Submit your manuscript at www.biomedcentral.com/submit
C Biomed Central 